\title{
OBITUARY: Richard Lewis Tweedie
}

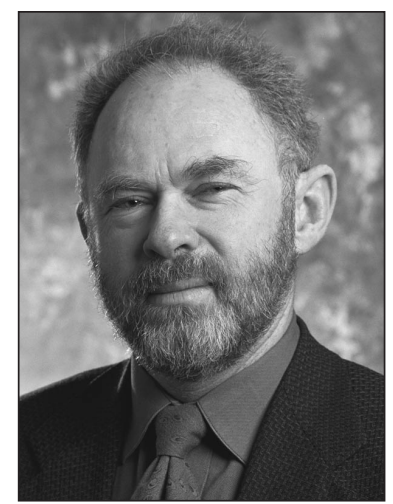

Richard Tweedie

\section{Introduction}

The sudden death of Richard Tweedie from a heart attack at the age of 53 on 7 June 2001 prematurely ended his outstanding career in applied probability modeling and statistical methodology. These fields have been enormously enriched by his contributions to research, teaching, administration, and professional service. His death at the peak of his creative output has saddened all of his colleagues.

Richard's professional career was rich and surprisingly varied. Richard Tweedie is perhaps best known for his fundamental contributions to the convergence theory of Markov chains. These began with his elegant Cambridge University thesis on convergence of Markov chains on general state spaces and continued with a series of important collaborators throughout his career. His early collaborators and mentors in this area are acknowledged in [80]. Section 2 reviews his work on Markov chains and related areas.

As well as this major focus on Markov chains, Richard also collaborated widely on other topics with fellow scientists as well as those in business. A personal account of his early collaborators is given in [66]. He is highly regarded by many working in applied areas such as queueing theory, systems theory, statistics, and Markov decision theory. The fact that he made such a significant impact on many related fields is due in part to his superb communication skills. His lectures were inspiring and full of humor, and his papers are models of clarity.

From his collaborations and consultancies arose a significant number of publications dealing with applications, as well as their theoretical aspects. Most recently he developed a major interest in statistical methods for epidemiology, with particular emphasis on Bayesian metaanalysis and publication bias. Section 3 reviews his contributions to statistics and epidemiology, and explores his interest in the application of these methodologies to the effects on health of environmental and occupational exposure to pollutants.

Richard was born in Leeton, an agricultural community in the Australian state of New South Wales. He matriculated from Leeton High School in 1964, winning a prestigious National Undergraduate Scholarship to attend the Australian National University (ANU). In 1969 he was awarded a first class honors degree in statistics, and received one of only two ANU Travelling Scholarships awarded annually, to support his graduate work at Cambridge University. In 
the six months between the end of the Australian and the start of the northern hemisphere academic years, Richard, in his typically energetic style, completed a Master of Arts degree by research. David Vere-Jones, then at ANU, encouraged Richard to work with David Kendall at Cambridge, and in 1972 he was awarded his PhD. This work appears as [1] and [2]. In Cambridge, Richard married Catherine Robertson whom he had met at ANU. More recently, in 1986, he was awarded a Doctor of Science degree by ANU on the basis of his major research achievements in the ergodic theory of Markov chains.

After completing his doctorate he returned to Australia in 1972 to become a postdoctoral fellow in the Statistics Department of ANU's Institute of Advanced Studies. In 1974, Joe Gani attracted him to the Division of Mathematics and Statistics (DMS) at the Commonwealth Scientific and Industrial Research Organisation (CSIRO). After a year's leave of absence in 1978 as Associate Professor at the University of Western Australia, he became the Senior Regional Officer of the Victorian Group of DMS. This period with CSIRO sowed the seeds of Richard's lifelong commitment to statistical consulting and scientific collaboration.

In 1981, shortly after the formation of SIROMATH by CSIRO and two industrial partners, he returned to Sydney to lead this mathematical, statistical, and software consulting company. For the next six years he built the enterprise up from four employees located in Sydney to approximately 40 located throughout most major Australian states. During his time at SIROMATH, he developed an extraordinary capacity to interest commercial organizations in the application of advanced mathematical and statistical modeling. The arrival in 1983 of his and Cathy's daughter, Marianne, added a new delight to his life.

Bond University, Australia's first private university, was established on the Gold Coast in Queensland in the late 1980s. Richard was recruited as one of four Foundation Deans in 1987 to set up its academic programs. The Deans had to meet the enormous challenge of creating degree programs that would attract full-fee paying students from Australia and overseas. His experiences at SIROMATH helped him to build a School of Information and Computing Sciences that integrated mathematical and statistical modeling with information technology. His twelve years at SIROMATH and Bond University placed heavy administrative demands on Richard. Remarkably, he continued his fundamental research in Markov chains and expanded the range of his interests to include research in statistical and epidemiological applications and methodology.

At the age of 43, Richard looked to the United States for his next career move. He took up a professorship in the Department of Statistics at Colorado State University in 1991, where he became Chairman from 1992 to 1997, and rapidly became involved in the US academic and professional scene. While at Colorado State University, he was able to concentrate on research to a greater extent than had been previously possible. Prior to 1991, Richard had limited opportunity to advise graduate students. With the exception of Pekka Tuominen who completed his University of Helsinki $\mathrm{PhD}$ in 1980, his other PhD students were at Colorado State University. There he was advisor to Zhiyong Zhu, Osnat Stramer, Bradley Biggerstaff, David Smith, Pei-de Chen, Gary Gadbury, Philippe Naveau, Jem Corcoran, and Sarah Streett.

Richard's developing research interests in statistical methods for epidemiological research helped lay the foundation for his next move to the University of Minnesota in 1999 to become Head of its Division of Biostatistics. He moved to Minneapolis with his characteristic enthusiasm in taking on a new and challenging role. Just prior to his death, Richard had led the development of new strategic plans for the Division and was looking forward to implementing these.

Richard was devoted to the statistical profession and, however busy, he found time to become involved in the organization, promotion, and scholarly activity of professional societies. His 
substantial contribution to the Statistical Society of Australia was recognized with Honorary Life Membership in 1998. In 1980, he was elected to the International Statistical Institute and became a member of its Bernoulli Society. He was elected a Fellow of the Institute of Mathematical Statistics in 1989 and of the American Statistical Association in 1997. He served as editor of the Annals of Applied Probability (1994-1996) and Statistical Science (2001), and was associate editor of a number of other leading journals.

Before reviewing Richard's contribution to applied probability and statistics, it would be appropriate to convey a sense of his personal qualities. In his professional career, Richard's capacity for work and his sometimes single-minded determination sustained him through many particularly challenging periods. He enjoyed the challenge of solving problems in research as well as in his managerial activities and his persistent and optimistic approach to work and life served him well.

Those who knew Richard remember him for his qualities of loyalty, charm, warmth, and generosity. He was a good conversationalist with an outstanding humor and quick wit. Being in his company was both memorable and stimulating. His ability to inspire those around him to do their best work was widely recognized. Younger colleagues and students remember Richard for his mentoring and encouragement and he took great pleasure in helping them get started in their careers. He was generous with his time, his advice, and his ideas.

All three of us feel honored to have had a deep association with Richard as a friend and a colleague. It was our privilege to have shared the intensity of his life and work.

\section{Markov processes}

Richard's research work in this area was concerned with the stability and ergodicity of Markov chains, and with methods for verifying basic structural assumptions such as irreducibility for general state-space models. He, together with his co-authors, extended most of this fundamental research to Markov processes, where the time parameter is continuous. He also developed a stability theory for Markov chains that could be readily applied in modeling a range of complex phenomena. The motivation for his research arose from collaboration with numerous researchers having expertise in applied areas.

\subsection{Convergence theory}

His earliest work was concerned with structural theory for positive operators, following the work of Vere-Jones and Seneta on positive matrices and Markov chains on a denumerable or finite sets [178], [179]. References [6] and [7] dealt with a representation theory for operators on a completely general state space. The structure of generalized Perron-Frobenius eigenvectors was developed, and a representation formula derived on the basis of an associated Martin boundary. This work formed the foundation of the general theory described in [172] which subsequently led to a significant body of research concerning large deviation asymptotics (see [170] and [171] for a starting point, and [163] and [167] for recent results and a survey).

Much of his research on the structural aspects of Markov processes emphasized the identification of subsets of the state space satisfying certain desirable conditions (e.g. [10], [16]). A relatively complete theory appeared in [29] and [30], and [86] contains a survey. These papers also extend and refine the classical Doeblin decomposition of a Markov process into a countable collection of ergodic, absorbing subsets, together with a transient set [164], [173].

Suppose that $R$ is a kernel obtained from sampling the semigroup,

$$
R(x, \mathrm{~d} y)=\int_{\mathbb{T}} P^{t}(x, \mathrm{~d} y) a(\mathrm{~d} t), \quad x, y \in \mathrm{X},
$$


where $a(\cdot)$ denotes a probability distribution on the time-set $\mathbb{T}$ and $\mathrm{X}$ denotes the state space of the process. The integral is interpreted as a sum when time is discrete. When time is continuous, and $a(\mathrm{~d} t)=\mathrm{e}^{-t} \mathrm{~d} t$, then this is the usual resolvent kernel. A positive kernel $T$ is called a continuous component of the semigroup $\left\{P^{t}: t \in \mathbb{T}\right\}$ if $R \geq T$ for some sampling distribution $a$, and $T(x, A)$ is lower semicontinuous for any $A \in \mathscr{B}$, where $\mathscr{B}$ is a countably generated, Borel $\sigma$-field on X. This idea originated in [29].

A Markov process is now called a $T$-process if the semigroup admits a continuous component satisfying $T(x, \mathrm{X})>0$ for all $x \in \mathrm{X}$. Richard's work in this area demonstrated that $T$-processes exhibit many of the properties of countable state-space Markov processes, with compact sets playing the role of finite sets. This assumption is a significant generalization of the strong Feller property that holds in many applications. For example, a hypoelliptic diffusion is always a $T$ process, but the strong Feller property may fail: consider, for example, the uniform deterministic motion on the unit circle (see [26], [29], [30] and [86]).

Richard's contributions to the stability theory of Markov processes are primarily based on the Lyapunov drift condition,

$$
\Delta V \leq-f+b s
$$

where $\Delta$ is the generator for the process, equal to $P-I$ when time is discrete; $V: X \rightarrow \mathbb{R}_{+}$is a Lyapunov function; $f: \mathbf{X} \rightarrow[1, \infty)$ is a given function; $b<\infty$; and the function $s: \mathbf{X} \rightarrow \mathbb{R}_{+}$ is in some sense small. For a $T$-process, the function $s$ may be taken as the indicator function of a compact set. The papers [12] and [17] provide significant generalizations of Pakes' and Foster's criteria for ergodicity based on versions of the drift condition (1). These approaches are all related to Lyapunov's second method for the stability of dynamical systems [165].

The Lyapunov drift condition is roughly equivalent to the balayage principle: if $h$ is a function that is subharmonic for a positive operator $K$, that is, if $K h \leq h$, and if $g$ is a positive-valued function satisfying

$$
K h \leq h-g,
$$

then the balayage principle asserts that $G g \leq h$, where $G$ is the potential kernel, $G=\sum_{k=0}^{\infty} K^{n}$. In developing the stability properties of a Markov process, the balayage principle is applied with $K=R-s \otimes v$, where $R$ is the kernel described above through sampling the transition semigroup, and $s$ and $v$ are, respectively, a positive function and measure, chosen so that $K$ is a positive operator. The significance of these bounds follows from the interpretation that $\mu=\nu G$ is always an invariant measure, provided that $\mu(\mathrm{X})<\infty$.

Various refinements of the consequences of a given Lyapunov drift-criterion were developed in a series of papers written from the late 1970s to the early 1990s [24], [25], [92], [94], [98], [134]. The characterization of geometric ergodicity, in particular, matured by the 1990s, through a research program led mainly by Richard. The most up-to-date results up to 1993 were given in the $V$-uniform ergodic theorem of [80]. If the Lyapunov condition (1) holds with $f=c V$ for some $c>0$, then the process is geometrically ergodic, and an exact converse also holds. Under this condition one can obtain convergence of the semigroup in an induced operator norm, and this implies the following uniform ergodic limit:

There exists an invariant distribution $\pi$ on $\mathcal{B}, a \delta_{0}>0$, and $b_{0}<\infty$ which satisfies the following condition: for all measurable functions $g: X \rightarrow \mathbb{R}$, and every initial condition $x \in \mathrm{X}$,

$$
\left|\int P^{t}(x, \mathrm{~d} y) g(y)-\int \pi(\mathrm{d} y) g(y)\right| \leq\|g\|_{V} b_{0} \mathrm{e}^{-\delta_{0} t} V(x), \quad t \in \mathbb{T},
$$

where $\|g\|_{V}:=\sup _{x \in \mathrm{X}}|g(x)| / V(x)$. 
This result is an extension of [166]. An explicit, if complex, bound on the rate of convergence in (2) is obtained in [92]. Subsequent work showed that the techniques could be refined considerably to produce bounds that were essentially the best possible, without assuming further structure [125]. In the context of stochastically monotone Markov chains and processes, considerable improvements proved possible, and Richard was also at the forefront of this area [101], [106], [107], [134].

These concepts have found applications in the theory of random matrices, recursive algorithms, communication theory, optimization, simulation, and queueing theory.

\subsection{Applications to queueing theory and time series}

Stochastic models specifically considered in Richard's work are random linear systems [58], and more general threshold models that can be used to approximate almost any conceivable nonlinear model. The existence of a causal, strictly stationary solution to general classes of threshold models was established in [76]. Extensions to continuous-time threshold models, including criteria for transience and for positive recurrence, are described in [104] and [105]. A further application is described in the review [135].

Richard enjoyed a fruitful collaboration with Søren Jarner in the last two years of his life. Markov chains with tight increments were analysed in [157], and sufficient conditions (in terms of the existence of moments) were given for polynomial ergodicity of a chain. This collaboration also led to two fundamental papers on the convergence of iterated random functions [145], [152], and related work on methods for simulation from a Dirichlet process in [156] based on [71]. Another of Richard's last papers [144] applied the computable bounds methods of [125] to the same problem.

A seminal result in the area of operations research is to be found in [45]; this provides a necessary and sufficient condition for the existence of a stationary distribution for a Markov chain. The implication is that a stable multiserver queue possesses a stationary distribution of operator-geometric form. These results have motivated a significant research program on operator methods for performance evaluation among operations researchers.

The stability of queueing models was treated in [35], [46], and [49], where exponential ergodicity was established for queueing models using Lyapunov function techniques. At that time, stability was not a new concept, but by the 1990s it was known that intuitive conditions for stability might not be sufficient for more complex networks of queues. In such models, the construction of a Lyapunov function requires significant intuition. Richard's research provided many generalizations of Foster's criterion, thus simplifying verification in complex models. Examples are the mean drift criterion of [14], the related multistep criteria of Malyšev [169], [87], criteria for the existence of moments [53], and criteria for the ergodicity of skip-free processes [23].

The impact of this research has been significant. In particular, the main result of [87] led to the averaging analysis of [162], which opened up several new research directions in optimization, stability, and performance evaluation of queueing models. A result of [88], based on [23], implies that a stable network model is, in fact, geometrically ergodic under minor statistical assumptions (see e.g. [168]). Consequently, one may apply results from the theory of large deviations, and other precise limit theorems, to obtain performance bounds or to analyse properties of a given stable scheduling rule for a stochastic network.

\subsection{Applications to MCMC and simulation}

Richard also made important contributions to the theory of Markov chain Monte Carlo (MCMC) algorithms on continuous state spaces. Ironically, he was unaware of the potential 
impact of his basic Markov processes work on MCMC until after [80] was completed. However, around 1993 he began to work on the subject which was to be his most active research field in the late 1990s.

It is important to recognize the importance of his first contribution to this area [100]. Given a target density $\pi$ on $\mathrm{X}$, the Metropolis-Hastings algorithm constructs a Markov chain with stationary distribution $\pi$. At each iteration, and conditional on $X_{t-1}=x$, it proposes a candidate new value $Y_{t}$ according to a transition density $q(x, \cdot)$. The new value of the Markov chain $X_{t}$ is chosen via the following mechanism: the new value $X_{t}=Y_{t}$ is accepted with conditional probability given by

$$
\alpha(x, y)=\min \left\{1, \frac{\pi(y) q(y, x)}{\pi(x) q(x, y)}\right\}
$$

otherwise, the current state-setting $X_{t}=X_{t-1}$ is retained. The resulting Markov chain is in detailed balance with the stationary density $\pi$.

Virtually any transition density $q(\cdot, \cdot)$ can be used in this construction. However, there are two generic and popular choices: (a) the independence sampler, where $q(x, \cdot) \sim p(\cdot)$ for some fixed probability distribution $p$ on $\mathrm{X}$, independent of $x$; and (b) the Metropolis-Hastings algorithm, where $q(\cdot, \cdot)$ is the transition density of a symmetric random walk, $q(x, y)=$ $p(|y-x|), x, y \in \mathrm{X}$, where $p$ is again fixed.

The paper [100] sets out general conditions relating properties of the distribution used in the simulation with the geometric ergodicity of the algorithm. It is shown that:

(i) The independence sampler is uniformly ergodic if and only if

$$
\sup _{y} \frac{\pi(y)}{p(y)}<\infty
$$

Where this condition fails, the independence sampler fails to be geometrically ergodic. This gives clear, practical guidance about the construction of proposal distributions. It also leads to a powerful and general method for constructing perfect simulation algorithms [161].

(ii) The Metropolis-Hastings algorithm is rarely uniformly ergodic for unbounded state spaces. For distributions on $X=\mathbb{R}^{1}$, the algorithm is geometrically ergodic if and only if the tails of the target density $\pi$ are bounded by $a \mathrm{e}^{-b|x|}$ for positive constants $a$ and $b$.

These results are based on the powerful drift and minorisation techniques to which Richard had devoted much of the previous 20 years, and which he had brought together in [80].

Given the structure of the chain, one may apply his bounds in the ergodic theorem (2) to address rates of convergence for the Metropolis-Hastings algorithm [176], [177], [138]. These results were generalized to multidimensional models in [102], with surprising consequences for apparently innocuous target densities.

Following his work on Metropolis-Hastings algorithms, Richard spearheaded a body of research on the more complex methods known as Langevin algorithms in [108] and [129]; this work led to more fundamental results on the stability of Langevin diffusions and their various discretisations in [128]. This research has been highly relevant to practical MCMC implementation, as is reviewed in [175]; many of the negative results (indicating the dangers of certain MCMC strategies) proved to be unexpected.

In the mid-1990s, the MCMC field was given fresh impetus by the discovery of the simple technique of simulation from the past [174]. Richard made fundamental contributions to this 
area [120], [122], [138], including a proof that successful coupling is equivalent to uniform ergodiciy. As was typical of Richard, this fundamental work was complemented by applications of perfect simulation [142], [143], [138], [153].

\section{Epidemiology and statistics}

The diversity of Richard's applied research exemplifies his varied collaborative and consultative abilities. He had a natural talent for combining rigorous yet accessible methodology with a pragmatic approach guided closely by collaboration with applied experts. He was also quick to introduce new computational and statistical methods to these areas of application.

Richard's early interest in applied work arose from his collaborative and consulting activities at CSIRO. Examples can be found in [15], [18], [32], [39], [40], [41], [42], [43], and [55]. One particular area of statistical methodology that he worked on in his CSIRO days, and which he recently returned to, was the use of Laplace transform estimation methods in models for stochastic processes (see [33], [48], [50], [54], [148], [149], and [150]). He has given a personal account of much of this work in [66].

Later, when Richard was working in SIROMATH, he continued to use consulting projects as the basis of published research. The work was varied and considerably more applied than that arising during his CSIRO days. Examples include [65], [67], [70], [72], [73], [117], and [118]. At that time, he began advising law firms on statistical methods for assessing the health risks of environmental and occupational exposures. The work was particularly challenging and led, with a series of co-authors, to increasingly sophisticated statistical models and methods. His epidemiological work was diverse and showed his flexibility in understanding a range of applications as well as in applying and extending appropriate methodology. This variety is visible in papers such as [79], [89], [95], [96], [97], [103], [116], [119], [126], and [131].

The main area of research arising from this work was meta-analysis and, more particularly, the topic of publication bias. Meta-analysis is used to combine the results of a number of studies of the same phenomenon. It provides a formal, quantitative approach for combining numerical size effects, such as the relative risk of a specific disease due to exposure to a specific factor, obtained from a collection of published studies. Publication bias refers to the possibility that, in attempting to collect all studies addressing the same issue, some studies may be overlooked for a variety of reasons. If these studies are omitted from a meta-analysis, then the conclusions may be skewed. Richard provided clear reviews of this area in [147] and [158]. His contributions varied from simple, readily applied graphical methods, to advanced Bayesian hierarchical modeling which relied on MCMC methods for their estimation. The range of applications was also considerably broadened to include meta-analysis of factors affecting other health outcomes (see [124], [130], [132], [155]). With a series of co-authors, Richard considered all these aspects of meta-analysis and publication bias and applied them to a variety of situations (see [95], [96], [112], [116], [124], [126], [131], and [132]).

University of Minnesota, Minneapolis

WiLliam T. M. DUNSMUIR

University of Illinois at Urbana-Champaign

SEAN P. MEYN

Lancaster University

GARETH RoBerts

May 2002 


\section{References}

\section{Publications of R. L. Tweedie}

Items authored or co-authored by R. L. Tweedie, listed chronologically.

[1] TweEdie, R. L. (1971). Stationary measures for random walk on a half line. Z. Wahrscheinlichkeitsth. 20, 28-46.

[2] Tweedie, R. L. (1971). Truncation procedures for non-negative matrices. J. Appl. Prob. 8, 311-320.

[3] TweEdie, R. L. (1973). The calculation of limit probabilities for denumerable Markov processes from infinitesimal properties. J. Appl. Prob. 10, 84-99.

[4] TweEdiE, R. L. (1974). A representation for invariant measures for transient Markov chains. Z. Wahrscheinlichkeitsth. 28, 99-112.

[5] Tweedie, R. L. (1974). Some ergodic properties of the Feller minimal process. Quart. J. Math. Oxford 25, $485-495$.

[6] Tweedie, R. L. (1974). $R$-theory for Markov chains on a general state-space. I. Solidarity properties and $R$-recurrent chains. Ann. Prob. 2, 840-864.

[7] TweEdiE, R. L. (1974). $R$-theory for Markov chains on a general state-space. II. $r$-subinvariant measures for $r$-transient chains. Ann. Prob. 2, 865-878.

[8] Tweedie, R. L. (1974). Quasi-stationary distributions for Markov chains on a general state-space. J. Appl. Prob. 11, 726-741.

[9] Tweedie, R. L. (1975). Truncation approximation of the limit probabilities for denumerable semi-Markov processes. J. Appl. Prob. 12, 161-163.

[10] Pollard, D. B. And Tweedie, R. L. (1975). $R$-theory for Markov chains on a topological state-space. I. $J$. London Math. Soc. 10, 389-400.

[11] Tweedie, R. L. (1975). Sufficient conditions for regularity, recurrence, and ergodicity of Markov processes. Math. Proc. Camb. Phil. Soc. 78, 125-136.

[12] Tweedie, R. L. (1975). Sufficient conditions for ergodicity and recurrence of Markov chains on a general state-space. Stoch. Process. Appl. 3, 385-403.

[13] TweEdiE, R. L. (1975). The robustness of positive recurrence and recurrence of Markov chains under perturbations of the transition probabilities. J. Appl. Prob. 12, 744-752.

[14] Tweedie, R. L. (1975). Relations between ergodicity and mean drift for Markov chains. Austral. J. Statist. 17, 96-102.

[15] Saunders, I. W. and Tweedie, R. L. (1976). The settlement of Polynesia by CYBER 76. Math. Scientist 1, 15-26.

[16] Pollard, D. B. And Tweedie, R. L. (1976). $R$-theory for Markov chains on a topological state-space. II. $Z$. Wahrscheinlichkeitsth. 34, 269-278.

[17] Tweedie, R. L. (1976). Criteria for classifying general Markov chains. Adv. Appl. Prob. 8, 737-771.

[18] McArthur, N. A., Saunders, I. W. And Tweedie, R. L. (1976). Small population isolates: a simulation study. J. Polynesian Soc. 85, 307-326.

[19] Nummelin, E. And Tweedie, R. L. (1976). Geometric ergodicity for a class of Markov chains. Ann. Sci. Univ. Clermont 61, 145-153.

[20] Tweedie, R. L. (1977). Modes of convergence of Markov chain transition probabilities. J. Math. Anal. Appl. 60, 280-291.

[21] Tweedie, R. L. (1977). Hitting times for Markov chains with application to state dependent queues. Bull. Austral. Math. Soc. 17, 97-107.

[22] Tweedie, R. L. (1977). Criteria for classifying general Markov chains (abstract). Adv. Appl. Prob. 9, $208-210$.

[23] Tweedie, R. L. And Westcott, M. (1978). First-passage times in skip-free processes. Stoch. Process. Appl. 7, 191-204.

[24] Nummelin, E. And Tweedie, R. L. (1978). Geometric ergodicity and $R$-positivity for general Markov chains. Ann. Prob. 6, 404-420.

[25] Isaacson, D. And Tweedie, R. L. (1978). Criteria for strong ergodicity of Markov chains. J. Appl. Prob. 15, 87-95.

[26] Arjas, E., Nummelin, E. And Tweedie, R. L. (1978). Uniform limit theorems for non-singular renewal and Markov renewal processes. J. Appl. Prob. 15, 112-125.

[27] Laslett, G. M., Pollard, D. B. and Tweedie, R. L. (1978). Techniques for establishing ergodic and recurrent properties of continuous-valued Markov chains. Naval. Res. Logistics Quart. 25, 455-472.

[28] Tweedie, R. L. (ed.) (1978). Proc. Conf. Spatial Patterns Process., Canberra, 12-14 May 1977 (Adv. Appl. Prob. 10 Spec. Suppl.). Applied Probability Trust, Sheffield.

[29] Tuominen, P. And Tweedie, R. L. (1979). Markov chains with continuous components. Proc. London Math. Soc. 38, 89-114. 
[30] Tweedie, R. L. (1979). Topological aspects of Doeblin decompositions for Markov chains. Z. Wahrscheinlichkeitsth. 46, 299-305.

[31] Tuominen, P. And Tweedie, R. L. (1979). The recurrence structure of general Markov processes. Proc. London Math. Soc. 39, 554-576.

[32] TweEdIE, R. L. (1979). Computerised anthropology—finding and settling Polynesian islands. Math. Spectrum 11, 75-81.

[33] Schum, H.-J. And Tweedie, R. L. (1979). Parameter estimation using transform estimation in time-evolving models. Math. Biosci. 45, 37-67.

[34] Tuominen, P. And Tweedie, R. L. (1979). Exponential decay and ergodicity of general Markov processes and their discrete skeletons. Adv. Appl. Prob. 11, 784-803.

[35] Tuominen, P. And Tweedie, R. L. (1979). Exponential ergodicity in Markovian queueing and dam models. J. Appl. Prob. 16, 867-880.

[36] Arjas, E., Nummelin, E. And Tweedie, R. L. (1980). Semi-Markov processes on a general state-space: $a$-theory and quasi-stationary properties. J. Austral. Math. Soc. A 30, 187-200.

[37] Athreya, K. B., Tweedie, R. L. And Vere-Jones, D. (1980). Asymptotic behaviour of point processes with Markov-dependent intervals. Math. Nachr. 99, 301-313.

[38] Tweedie, R. L. (1980). Perturbations of countable Markov chains. Ann. Inst. Statist. Math. A. 32, $283-290$.

[39] Young, R. R., Anderson, N., Overend, D., Tweedie, R. L., Malafant, K. W. J. and Preston, G. A. N. (1980). The effect of temperature on times to hatching of eggs of the nematode Ostertagia Circumcinta. Parasitology 81, 477-491.

[40] Young, R. R., Nicholson, R. M., Tweedie, R. L. And SchuH, H.-J. (1980). Quantitative modeling and prediction of development times of the free living stages of Ostertagia ostertagi under controlled and field conditions. Parasitology 81, 493-505.

[41] Low, W. A., Tweedie, R. L., Edwards, C. B. H., Hodder, R. M., Malafant, K. W. J. and Cunningham R. B. (1981). The influence of environment on daily maintenance behaviour of free-ranging shorthorn cows in Central Australia. I: general introduction and descriptive analysis of day-long activities. Appl. Animal Ethol. 7, 11-26.

[42] Low, W. A., Tweedie, R. L., Edwards, C. B. H., Hodder, R. M., Malafant, K. W. J. and Cunningham, R. B. (1981). The influence of environment on daily maintenance behaviour of free-ranging shorthorn cows in Central Australia. II: multivariate analysis of duration and incidence of activities. Appl. Animal Ethol. 7, 27-38.

[43] Low, W. A., Tweedie, R. L., Edwards, C. B. H., Hodder, R. M., Malafant, K. W. J. and Cunningham, R. B. (1981). The influence of environment on daily maintenance behaviour of free-ranging shorthorn cows in Central Australia. III: detailed analysis of sequential behavior patterns and integrated discussion. Appl. Animal Ethol. 7, 39-56.

[44] Tweedie, R. L. (1981). Criteria for ergodicity, exponential ergodicity and strong ergodicity of Markov processes. J. Appl. Prob. 18, 122-130.

[45] TweEdIE, R. L. (1982). Operator-geometric stationary distributions for Markov chains, with application to queueing models. Adv. Appl. Prob. 14, 368-391.

[46] Brockwell, P. J., Resnick, S. I. And Tweedie, R. L. (1982). Storage processes with general release rule and additive input. Adv. Appl. Prob. 14, 392-433.

[47] Malafant, K. W. J. and Tweedie, R. L. (1982). Computer production of kinetograms. Appl. Animal Ethol. 8, 179-187.

[48] Trajstman, A. C. And Tweedie, R. L. (1982). Techniques for estimating parameters in Bartoszynski's virus model. Math. Biosci. 58, 277-307.

[49] TweEdIE, R. L. (1982). Criteria for rates of convergence of Markov chains, with application to queueing and storage theory. In Papers in Probability, Statistics and Analysis (London Math. Soc. Lecture Notes 79), eds J. F. C. Kingman and G. E. H. Reuter, Cambridge University Press, pp. 260-276.

[50] Feigin, P. D., Belyea, C. and Tweedie, R. L. (1983). Weighted area techniques for explicit parameter estimation in hierarchical models. Austral. J. Statist. 25, 1-16.

[51] Theodorescu, R. And Tweedie, R. L. (1983). Solidarity properties and a Doeblin decomposition for a class of non-Markovian stochastic processes. Metrika 30, 37-47.

[52] Sennott, L. I., Humblet, P. And Tweedie, R. L. (1983). Mean drifts and the non-ergodicity of Markov chains. Operat. Res. 31, 783-789.

[53] Tweedie, R. L. (1983). The existence of moments for stationary Markov chains. J. Appl. Prob. 20, 191-196.

[54] Leedow, M. I. AND Tweedie, R. L. (1983). Weighted area techniques for the estimation of the parameters of a growth curve. Austral. J. Statist. 25, 310-320.

[55] Henstridge, J. D. And Tweedie, R. L. (1984). A model for the growth pattern of mutton birds. Biometrics 40, 917-925. 
[56] Tweedie, R. L. ANd Hall, N. (1984). A rotational sampling framework for NSW health statistics (abstract). Community Health Studies 8, 144.

[57] ArJas, E., HaAra, P. And Tweedie, R. L. (1984). A system model with interacting components: renewal-type results (abstract). Adv. Appl. Prob. 16, 7-8.

[58] Feigin, P. D. And Tweedie, R. L. (1985). Random coefficient autoregressive processes: a Markov chain analysis of stationarity and finiteness of moments. J. Time Ser. Anal. 6, 1-14.

[59] Seneta, E. And Tweedie, R. L. (1985). Moments for stationary and quasi-stationary distributions of Markov chains. J. Appl. Prob. 22, 148-155.

[60] Arjas, E., HaAra, P. and Tweedie, R. L. (1985). Reliability in multi-component systems: structure and convergence to stationary behaviour. Optimisation 16, 297-311.

[61] Feigin, P. D. And Tweedie, R. L. (1985). Markov-chain ergodicity and time-series models (abstract). Stoch. Process. Appl. 19, 17.

[62] Tweedie, R. L. (1986). The existence of moments for Markov and semi-Markov processes with application to birth-death and stress release models. In Proc. 1st Pacific Statist. Cong., eds I. Francis, B. J. F. Manly, F. C. Lam, North-Holland, Amsterdam, pp. 147-149.

[63] Hall, J., Hall, N. And Tweedie, R. L. (1986). A longitudinal study of health changes following the introduction of Medicare. In Economics and Health 1985, Proc. 7th Austral. Conf. Health Econom. (Austral. Studies Health Service Administration 56), eds J. Butler. and D. P. Doessel, University of New South Wales, pp. 81-102.

[64] Tweedie, R. L. (1986). Recurrence criterion. In Encyclopaedia of Statistical Sciences, Vol. 7, eds S. Kotz, N. L. Johnson and C. B. Read, John Wiley, New York, pp. 656-658.

[65] Tweedie, R. L. (1986). Working with official statistics: some SIROMATH experiences. Austral. J. Statist. 28, 265-286.

[66] TweEdIE, R. L. (1986). In and out of applied probability in Australia. In The Craft of Probabilistic Modelling (Appl. Prob. Ser.), ed. J. Gani, Springer, New York, pp. 291-308.

[67] Tweedie, R. L. (1987). Statistical consulting in Australia. Liaison 2, 37-40.

[68] Tweedie, R. L. (1988). Invariant measures for Markov chains with no irreducibility assumptions. In $A$ Celebration of Applied Probability (J. Appl. Prob. Spec. Vol. 25A), ed. J. Gani, Applied Probability Trust, Sheffield, pp. 275-285.

[69] Tweedie, R. L. (1988). Return state. In Encyclopaedia of Statistical Sciences, Vol. 8, eds eds S. Kotz, N. L. Johnson and C. B. Read, John Wiley, New York, pp. 124-125.

[70] TweEdIE, R. L. (1989). Shaping tomorrow's university. In Proc. SOST'89, eds R. Clark and J. Cameron, ACS, Sydney, pp. 427-439.

[71] Feigin, P. D. AND Tweedie, R. L. (1989). Linear functionals and Markov chains associated with the Dirichlet process. Math. Proc. Camb. Phil. Soc. 105, 579-585.

[72] Tweedie, R. L. (1989). Total quality management and information technology. Internat. J. Value-Based Manag. 2, 111-125.

[73] Dunsmuir, W. T. M., Tweedie, R. L., Flack, L. and Mengersen, K. E. (1989). Modelling of transitions between employment states for young Australians. Austral. J. Statist. 31A, 165-196.

[74] Tweedie, R. L. (1990). Criteria for rates of convergence to stationarity in Markovian queueing models with application to the GSPP/GSPP/1 queue. In Proc. 4th Austral. Teletraffic Res. Seminar, ed. R. J. Harris, Bond University.

[75] Tweedie, R. L. (1991). Pitman Medal awarded to E. J. Hannan. Austral. J. Statist. 33, 1-4

[76] Brockwell, P. J., Liu, J. ANd Tweedie, R. L. (1992). On the existence of a stationary threshold autoregressivemoving average model. J. Time Ser. Anal. 13, 95-107.

[77] Tweedie, R. L. (1992). Comments on the Committee for New Researchers Guidelines. Statist. Sci. 7, $263-264$.

[78] Meyn, S. P. ANd Tweedie, R. L. (1992). Stability of Markovian processes I: criteria for discrete-time chains. Adv. Appl. Prob. 24, 542-574.

[79] Tweedie, R. L. And Mengersen, K. L. (1992). Lung cancer and passive smoking: reconciling the biochemical and epidemiological approaches. British J. Cancer 66, 700-705.

[80] Meyn, S. P. AND Tweedie, R. L. (1993). Markov Chains and Stochastic Stability. Springer, London.

[81] Meyn, S. P. and Tweedie, R. L. (1993). The Doeblin decomposition. Contemp. Math. 149, 211-225.

[82] Meyn, S. P. And Tweedie, R. L. (1993). Generalised resolvents and Harris recurrence of Markov processes. Contemp. Math. 149, 227-250.

[83] Meyn, S. P. ANd Tweedie, R. L. (1993). Stability of Markovian processes II: continuous-time and sampled chains. Adv. Appl. Prob. 25, 487-517.

[84] Meyn, S. P. And Tweedie, R. L. (1993). Stability of Markovian processes III: Foster-Lyapunov criteria for continuous-time processes. Adv. Appl. Prob. 25, 518-548.

[85] Tweedie, R. L., Zhu, Z. Y. And Choy, S. L. (1993). Parameter estimation using Laplace transforms in the M/M/1 queue. Tech. Rep. 93/6, Department of Statistics, Colorado State University. 
[86] Tweedie, R. L. (1994). Computable convergence rates and geometric ergodicity for Markovian queueing systems. In Proc. 31 st Allerton Conf. Commun. Control Comput. (October 1993), eds D. P. Sarwate and P. van Dooren, University of Illinois Press, Champaign, IL, pp. 404-412.

[87] Meyn, S. P. and Tweedie, R. L. (1994). State-dependent criteria for convergence of Markov chains. Ann. Appl. Prob. 4, 149-168.

[88] Spieksma, F. M. And Tweedie, R. L. (1994). Strengthening ergodicity to geometric ergodicity for Markov chains. Commum. Statist. Stoch. Models 10, 45-74.

[89] Tweedie, R. L., Mengersen, K. L. And Eccleston, J. A. (1994). Garbage in, garbage out: can statisticians quantify the effects of poor data? Chance 7, 20-27.

[90] Tweedie, R. L. (1994). Topological conditions enabling use of Harris methods in discrete and continuous time. Acta Appl. Math. 34, 175-188.

[91] Stramer, O. and Tweedie, R. L. (1994). Stability and instability of continuous time Markov processes. In Probability, Statistics and Optimization: a Tribute to Peter Whittle, ed. F. P. Kelly, John Wiley, London, pp. $173-183$.

[92] Meyn, S. P. and Tweedie, R. L. (1994). Computable bounds for geometric convergence rates of Markov chains. Ann. Appl. Prob. 4, 981-1011.

[93] Meyn, S. P. And Tweedie, R. L. (1994). A survey of Foster-Lyapunov conditions for general state-space Markov processes. In Proc. Workshop Stoch. Stability Stoch. Stabilization (Metz, France, June 1993), Springer, Berlin.

[94] Tuominen, P. And Tweedie, R. L. (1994). Subgeometric rates of convergence of $f$-ergodic Markov chains. Adv. Appl. Prob. 26, 775-798.

[95] Biggerstaff, B., Tweedie, R. L. and Mengersen, K. L. (1994). Passive smoking in the workplace: classical and Bayesian meta-analyses. Internat. Arch. Occupational Environmental Health 66, 269-277.

[96] Tweedie, R. L. And Mengersen, K. L. (1995). Meta-analytic approaches to dose-response relationships, with application in studies of lung cancer and exposure to environmental tobacco smoke. Statist. Medicine 14, $545-569$

[97] Mengersen, K. L., Tweedie, R. L. and Biggerstaff, B. (1995). The impact of method choice in metaanalysis. Austral. J. Statist. 37, 19-44.

[98] Down, D., Meyn, S. P. And Tweedie, R. L. (1995). Exponential and uniform ergodicity of Markov processes. Ann. Prob. 23, 1671-1691.

[99] Mengersen, K. L. And Tweedie, R. L. (1995). Comments on 'Convergence of Markov chain Monte Carlo algorithms' by N. G. Polson. In Bayesian Statistics 5, Proc. 5th Valencia Internat. Meeting (5-9 June 1994, Alicante), eds J. M. Bernardo, J. O. Berger, A. P. Dawid and A. F. M. Smith, Oxford University Press, pp. 317318.

[100] Mengersen, K. L. And Tweedie, R. L. (1996). Rates of convergence of the Hastings and Metropolis algorithms. Ann. Statist. 24, 101-121.

[101] Lund, R. AND TweEdIE, R. L. (1996). Geometric convergence rates for stochastically ordered Markov chains. Math. Operat. Res. 21, 182-194.

[102] Roberts, G. O. AND Tweedie, R. L. (1996). Geometric convergence and central limit theorems for multidimensional Hastings and Metropolis algorithms. Biometrika 83, 95-110.

[103] Tweedie, R. L., Scott, D. J., Biggerstaff, B. J. and Mengersen, K. L. (1996). Bayesian meta-analysis, with application to studies of ETS and lung cancer. Lung Cancer 14, S171-S194.

[104] Stramer, O., Brockwell, P. J. and Tweedie, R. L. (1996). Continuous-time threshold AR(1) models. Adv. Appl. Prob. 28, 728-746.

[105] Stramer, O., Tweedie, R. L. And Brockwell, P. J. (1996). Existence and stability of continuous time threshold ARMA precesses. Statist. Sinica 6, 715-732.

[106] Meyn, S. P., Lund, R. ANd TweEdie, R. L. (1996). Rates of convergence of stochastically monotone Markov processes. Ann. Appl. Prob. 6, 218-237.

[107] Scott, D. J. And Tweedie, R. L. (1996). Explicit rates of convergence of stochastically monotone Markov chains. In Proc. Athens Conf. Appl. Prob. Time Ser. Anal., eds C. C. Heyde, Yu. V. Prohorov, R. Pyke and S. T. Rachev, Springer, New York, pp. 176-191.

[108] Roberts, G. O. ANd Tweedie, R. L. (1996). Exponential convergence of Langevin diffusions and their discrete approximations. Bernoulli 2, 341-363.

[109] TweEdIE, R. L. (1996). Electronic publishing in the IMS: a step forward. IMS Bull. 25, 627-629.

[110] LaFleur, B., Taylor, S. J., Smith, D. D. and Tweedie, R. L. (1996). Bayesian assessment of publication bias in meta-analyses of cervical cancer and oral contraceptives. In Proc. Epidemiology Section 1996 Joint Statist. Meetings, American Statistical Association, Alexandria, VA, pp. 32-37.

[111] Chen, P. And Tweedie, R. L. (1997). Orthogonal measures and absorbing sets for Markov chains. Math. Proc. Camb. Phil. Soc. 121, 101-113. 
[112] Biggerstaff, B. J. AND Tweedie, R. L. (1997). Incorporating variability in estimates of heterogeneity in the random effects model in meta-analysis. Statist. Medicine 16, 753-768.

[113] Tweedie, R. L. (1997). Annals of Applied Probability. In Encyclopedia of Statistical Sciences, Update Vol. 1, eds S. Kotz, C. B. Read and D. L. Banks, John Wiley, New York, pp. 30-32.

[114] Stramer, O. and Tweedie, R. L. (1997). Existence and stability of weak solutions to stochastic differential equations with non-smooth coefficients. Statist. Sinica 7, 577-594.

[115] TAYloR, S. J. AND TweEdie, R. L. (1997). Assessing sensitivity to multiple factors in calculating attributable risk. Environmetrics 8, 351-372.

[116] Givens, G. H., Smith, D. D. And Tweedie, R. L. (1997). Publication bias in meta-analysis: a Bayesian dataaugmentation approach to account for issues exemplified in the passive smoking debate (with discussion). Statist. Sci. 12, 221-250.

[117] TweEdie, R. L. (1998). Consulting: real problems, real interactions, real outcomes. Statist. Sci. 13, 1-3.

[118] Hall, N. and Tweedie, R. L. (1998). Queueing at the tax office. Statist. Sci. 13, 18-23.

[119] Tweedie, R. L. (1998). Assessing sensitivity to data problems in epidemiological meta-analyses. Proc. 51st Session ISI (Istanbul, August 1997), Vol. 3, International Statistical Institute, Amsterdam, pp. 556-559.

[120] Foss, S. G. ANd Tweedie, R. L. (1998). Perfect simulation and backward coupling. Commun. Statist. Stoch. Models 14, 187-203.

[121] TweEdIE, R. L. (1998). Roles for societies in statistical education statistical education--expanding the network. In Proc. 5th ICOTS, ed. L. Pereira-Mendoza, International Statistical Institute, Amsterdam, pp. 439444.

[122] Foss, S. G., Tweedie, R. L. And Corcoran, J. N. (1998). Simulating the invariant measures of Markov chains using backward coupling at regeneration time. Prob. Eng. Inf. Sci. 12, 303-320.

[123] Tweedie, R. L. (1998). Truncation approximations of invariant measures for Markov chains. J. Appl Prob. 35, 517-536.

[124] Duval, S. And Tweedie, R. L. (1998). Practical estimates of the effect of publication bias in meta-analysis. Austral. Epidemiol. 5, 14-17.

[125] Roberts, G. O. ANd Tweedie, R. L. (1999). Bounds on regeneration times and convergence rates for Markov chains. Stoch. Process. Appl. 80, 211-229. (Corrigendum: 91 (2001), 337-338.)

[126] Mengersen, K. L., Merrilees, M. and Tweedie, R. L. (1999). Environmental tobacco smoke and ischaemic heart disease: a case study in applying causal criteria. Internat. Arch. Occupational Environmental Health 72, Suppl. R1-R40.

[127] Mengersen, K. L. And Tweedie, R. L. (1999). Calculating accuracy rates from multiple assessors with limited information. Amer. Statistician 53, 233-238.

[128] Stramer, O. and Tweedie, R. L. (1999). Langevin-type models I: diffusions with given stationary distributions, and their discretizations. Methodol. Comput. Appl. Prob. 1, 283-306.

[129] Stramer, O. and Tweedie, R. L. (1999). Langevin-type models II: self-targeting candidates for MCMC algorithms. Methodol. Comput. Appl. Prob. 1, 307-328.

[130] Smith, D. D., Givens, G. H. And Tweedie, R. L. (2000). Adjustment for publication bias and quality bias in Bayesian meta-analysis. In Meta-analysis in Medicine and Health Policy, eds D. Berry and D. Stangl, Marcel Dekker, New York, pp. 277-304.

[131] Duval, S. J. AND Tweedie, R. L. (2000). A nonparametric 'trim and fill' method of assessing publication bias in meta-analysis. J. Amer. Statist. Assoc. 95, 89-98.

[132] Duval, S. J. And Tweedie, R. L. (2000). Trim and fill: a simple funnel plot based method of testing and adjusting for publication bias in meta-analysis. Biometrics, 56, 276-284.

[133] Sutton, A. J., Duval, S. J., Tweedie, R. L., Abrams, K. R. and Jones, D. R. (2000). Empirical assessment of effect of publication bias on meta-analyses. British Medical J. 320, 1574-1577.

[134] Roberts, G. O. And Tweedie, R. L. (2000). Rates of convergence of stochastically monotone stochastic processes. J. Appl. Prob. 37, 359-373.

[135] Grunwald, G. K., Hyndman, R. J., Tedesco, L. and Tweedie, R. L. (2000). Non-Gaussian conditional linear AR(1) models. Austral. N. Z. J. Statist. 42, 479-495.

[136] Sexton, K., Greaves, I. A., Church, T. R., Adgate, J. L., Ramachandran, G., Tweedie, R. L., Fredrickson, A., Geisser, M., Sikorski, M., Fischer, G., Jones, D. And Ellringer, P. (2000). A schoolbased strategy to assess children's environmental exposures and related health effects in economically disadvantaged urban neighborhoods. J. Exposure Anal. Environmental Epidemiol. 10, 682-694.

[137] TweEdIE, R. L. (2001). Markov chains: structure and applications. In Handbook of Statistics, Vol. 19, Stochastic Processes: Theory and Methods, eds D. N. Shanbhag and C. R. Rao, Elsevier, Amsterdam, pp. 817-851.

[138] Corcoran, J. N. and Tweedie, R. L. (2001). Perfect sampling for ergodic Harris chains. Ann. Appl. Prob. 11, 438-451.

[139] Tweedie, R. L. (2001). Drift conditions and invariant measures for Markov chains. Stoch. Process. Appl. 92, $345-354$. 
[140] Roberts, G. O. AND Tweedie, R. L. (2001). Geometric $L^{2}$ and $L^{1}$ convergence are equivalent for reversible Markov chains. In Probability, Statistics and Seismology (J. Appl. Prob. Spec. Vol. 38A), ed. D. J. Daley, Applied Probability Trust, Sheffield, pp. 37-41.

[141] Wall, M., Boen, J. And Tweedie, R. L. (2001). An effective CI for the mean with samples of size 1 and 2. Amer. Statistician 55, 102-105.

[142] Tweedie, R. L. And Corcoran, J. N. (2001). Perfect sampling and queuing models. In Proc. 38th Annual Allerton Conf. Commun. Control Comput. (4-6 October 2000), University of Illinois Press, Champaign, IL, pp. 116-124.

[143] Henderson, S. And Tweedie, R. L. (2001). Perfect sampling for Markov chains arising from discrete event simulation. In Proc. 38th Annual Allerton Conf. Commun. Control Comput. (4-6 October 2000), University of Illinois Press, Champaign, IL, pp. 1125-1134.

[144] Guglielmi, A. And Tweedie, R. L. (2001). Markov chain Monte Carlo estimation of the law of the mean of a Dirichlet process. Bernoulli 4, 573-592.

[145] Jarner, S. F. And Tweedie, R. L. (2001). Locally contracting iterated functions and stability of Markov chains. J. Appl. Prob. 38, 494-507.

[146] Stramer, O. AND Tweedie, R. L. (2001). Existence and stability of weak solutions to stochastic differential equations with non-smooth coefficients. Statist. Sinica 7, 577-593.

[147] Tweedie, R. L. (2001). Meta-analysis: overview. In International Encyclopedia of Social and Behavioral Sciences, Vol. 14, eds N. J. Smelser and P. B. Baltes, Elsevier, Amsterdam, pp. 9717-9724.

[148] Hoeting, J. A. AND Tweedie, R. L. (2001). Parameter estimation for models of biological stage-frequency data, In Proc. Graybill Conf. Linear Models (13-15 June 2001, Colorado State University).

[149] Hoeting, J. A. And Tweedie, R. L. (2001). Transform estimation of parameters for stage-frequency data. Tech. Rep. 2001-2, Department of Statistics, Colorado State University. Available at http://www.stat.colostate.edu/ Documents/.

[150] Hoeting, J. A., Johnson, D. S. And Tweedie, R. L. (2001). Empirical transform estimation of parameters in the monomolecular growth model. Tech. Rep. 2001-5, Department of Statistics, Colorado State University. Available at http://www.stat.colostate.edu/Documents/.

[151] Fonseca, G. AND TweEdie, R. L. (2001). Stationary measures for non-irreducible non-continuous Markov chains with time series applications. Submitted.

[152] Jarner, S. F. And Tweedie, R. L. (2001). Stability properties of Markov chains defined via iterated random functions. Submitted.

[153] Cooper, W. L. AND TweEdie, R. L. (2001). Perfect simulation of an inventory model for perishable products. Submitted.

[154] Tweedie, R. L. (2001). Convergence of Markov chains from all starting points, with applications to MetropolisHastings algorithms. Submitted.

[155] Saleh, K. J., Dykes, D. C., Ravichandran, A., Saleh, R. M., Mohamed, K., Gioe, T. J., Heck, D. A. AND TweEdie, R. L. (2001). Functional outcome following total knee athroplasty revision: a meta-analysis. Submitted.

[156] JARNER, S. F. AND TweEDIE, R. L. (2001). Convergence rates and moments of Markov chains associated with the mean of Dirichlet processes. Submitted.

[157] JARnER, S. F. AND TweEdIE, R. L. (2001). Necessary conditions for geometric and polynomial ergodicity of random walk-type Markov chains. Submitted.

[158] Tweedie, R. L. (2002). Meta-analysis. In Encyclopedia of Environmetrics, eds A. H. El-Shaarawi and W. W. Piegorsch, John Wiley, New York.

[159] Tweedie, R. L. (2002). Environmental tobacco smoke. In Encyclopedia of Environmetrics, eds A. H. ElShaarawi and W. W. Piegorsch, John Wiley, New York.

[160] Tweedie, R. L. ANd Corcoran, J. N. (2002). Perfect sampling from independent Metropolis-Hastings chains. J. Statist. Planning Infer. 104, 297-314.

\section{Other references}

[161] Breyer, L. and Roberts, G. O. (2001). Catalytic perfect simulation. Methodol. Comput. Appl. Prob. 3, $161-177$.

[162] DaI, J. G. (1996). A fluid-limit model criterion for instability of multiclass queueing networks. Ann. Appl. Prob. 6, 751-757.

[163] De AcostA, A. AND Ney, P. (1998). Large deviation lower bounds for arbitrary additive functionals of a Markov chain. Ann. Prob. 26, 1660-1682.

[164] Doeblin, W. (1940) Éléments d'une théorie générale des chaînes simples constantes de Markoff. Ann. École Norm. (3) 57, 61-111.

[165] HASḾInSKIĬ, R. Z. (1980). Stochastic Stability Of Differential Equations. Sijthoff and Noordhoff, Alphen aan den Rijn. (Translated from the Russian by D. Louvish.) 
[166] Hordiuk, A. AND Spieksma, F. M. (1992). On ergodicity and recurrence properties of a Markov chain with an application. Adv. Appl. Prob. 24, 343-376.

[167] Kontoyiannis, I. And Meyn, S. P. (2002). Spectral theory and limit theorems for geometrically ergodic Markov processes. To appear in Ann. Prob.

[168] Kumar, P. R. And Meyn, S. P. (1996). Duality and linear programs for stability and performance analysis of queuing networks and scheduling policies. IEEE Trans. Automatic Control 41, 4-17.

[169] MALYšEv, V. A. (1972). Classification of two-dimensional positive random walks and almost linear semimartingales. Soviet Math. Dokl. 13, 136-139.

[170] Ney, P. AND Nummelin, E. (1987). Markov additive processes I: eigenvalue properties and limit theorems. Ann. Prob. 15, 561-592.

[171] Ney, P. And Nummelin, E. (1987) Markov additive processes II: large deviations. Ann. Prob. 15, 593-609.

[172] Nummelin, E. (1984). General Irreducible Markov Chains and Nonnegative Operators. Cambridge University Press.

[173] ORey, S. (1971). Lecture Notes on Limit Theorems for Markov Chain Transition Probabilities (Van Nostrand Reinhold Math. Studies 34). Van Nostrand Reinhold, London.

[174] Propp, J. G. AND Wilson, D. B. (1996). Exact sampling with coupled Markov chains and applications to statistical mechanics. Random Structures Algorithms 9, 223-252.

[175] Roberts, G. O. (2002). Linking theory and practice of MCMC. To appear in Highly Structured Stochastic Systems, eds P. Green, N. Hjort and S. Richardson, Oxford University Press.

[176] Roberts, G. O. and Rosenthal, J. S. (1999). Convergence of the slice sampler. J. R. Statist. Soc. B 61, 643-660.

[177] Roberts, G. O. and Rosenthal, J. S. (2002). The polar slice sampler. To appear in Stoch. Models.

[178] Seneta, E. (1981). Nonnegative Matrices and Markov Chains, 2nd edn. Springer, New York.

[179] Vere-Jones, D. (1967). Ergodic properties of nonnegative matrices. I. Pacific J. Math. 22, 361-386. 